\title{
8 Was gilt, wenn kein Bebauungsplan existiert?
}

Wenn kein Bebauungsplan für einen Standort existiert, muss geprüft werden, in welchem Bereich das Vorhaben geplant ist. Dabei unterscheidet man zwischen Außenbereich und (unbeplantem) Innenbereich.

Der Außenbereich wird negativ definiert. Danach ist Außenbereich alles, was nicht im Geltungsbereich eines Bebauungsplan oder im nicht beplanten Innenbereich liegt. ${ }^{1}$

Der Innenbereich beinhaltet gemäß $\S 34$ Abs. 1 S. 1 BauGB Gebiete innerhalb im Zusammenhang bebauter Ortsteile. Ob ein solcher Bebauungszusammenhang vorliegt und ob dieser zu einem Ortsteil gehört, muss im Einzelfall geprüft werden. ${ }^{2}$

[Anmerkung: „Ein Ortsteil ist jeder Bebauungskomplex im Gebiet einer Gemeinde, der nach der Zahl der vorhandenen Bauten ein gewisses Gewicht besitzt und Ausdruck einer organischen Siedlungsstruktur ist. "33

Kriterien für einen Bebauungszusammenhang sind u. a. eine ,tatsächlich aufeinanderfolgende, eben zusammenhängende Bebauung “4 und der „Eindruck der Geschlossenheit und Zusammengehörigkeit $^{* 5}$.]

\section{Literatur}

Ernst/Zinkahn/Bielenberg/Krautzberger, BauGB, 130. Ergänzungslieferung, München 2018

Spannowsky/Uechtritz, Beck'scher Online-Kommentar BauGB, Stand: 01.11.2018, Edition:

43, München

1 So u. a. Söfker-Ernst/Zinkahn/Bielenberg/Krautzberger, BauGB, § 35 Rn. 13

2 Vgl. Spannowsky-Spannowsky/Uechtritz, Beck'scher Online-Kommentar, BauGB § 34 Rn. 22, Stand: 01.11 .2018

3 Söfker-Ernst/Zinkahn/Bielenberg/Krautzberger, BauGB, §35 Rn. 14; BVerwG Urteil vom 6. 11. 1968, Az. 4 C 31.66 und Az. 4 C 47.68; BVerwG Urteil vom 17. 2. 1984, Az. 4 C 56.79

4 Söfker-Ernst/Zinkahn/Bielenberg/Krautzberger, BauGB, § 34 Rn. 18; BVerwG, Urt. vom 6. 11. 1968, Az. 4 C 2.66

5 Spannowsky-Spannowsky/Uechtritz, Beck'scher Online-Kommentar, BauGB § 34 Rn. 23, Stand: 01.11.2018; BVerwG, ZfBR 1999, 229

(C) Springer Fachmedien Wiesbaden GmbH, ein Teil von Springer Nature 2019

A. Wirth und A. Schneeweiß, Öffentliches Baurecht praxisnah,

https://doi.org/10.1007/978-3-658-25720-0_8 